\title{
Optimization of microwave-assisted extraction of flavonoids from young barley leaves**
}

\author{
Tian Gao ${ }^{1}$, Min Zhang ${ }^{1,2 *}$, Zhongxiang Fang ${ }^{3}$, and Qifeng Zhong ${ }^{4}$ \\ ${ }^{1}$ State Key Laboratory of Food Science and Technology, Jiangnan University, 214122 Wuxi, Jiangsu, China \\ ${ }^{2}$ Jiangnan University (Yangzhou) Food Biotechnology Institute, Yangzhou 225002, China \\ ${ }^{3}$ Faculty of Veterinary and Agricultural Sciences, University of Melbourne, Parkville, Victoria 3010, Australia \\ ${ }^{4}$ Haitong Food Group Company, Zhejiang Cixi, 315300, China
}

Received February 16, 2016; November 14, 2016

\begin{abstract}
A b s t r a c t. A central composite design combined with response surface methodology was utilized to optimise microwave-assisted extraction of flavonoids from young barley leaves. The results showed that using water as solvent, the optimum conditions of microwave-assisted extraction were extracted twice at $1.27 \mathrm{~W} \mathrm{~g}^{-1}$ microwave power and liquid-solid ratio $34.02 \mathrm{ml} \mathrm{g}^{-1}$ for $11.12 \mathrm{~min}$. The maximum extraction yield of flavonoids (rutin equivalents) was $80.78 \pm 0.52 \%$. Compared with conventional extraction method, the microwave-assisted extraction was more efficient as the extraction time was only $6.18 \%$ of conventional extraction, but the extraction yield of flavonoids was increased by $5.47 \%$. The main flavonoid components from the young barley leaf extract were probably $33.36 \%$ of isoorientin-7-O-glueoside and $54.17 \%$ of isovitexin-7-O-glucoside, based on the HPLC-MS analysis. The barley leaf extract exhibited strong reducing power as well as the DPPH radical scavenging capacity.

$\mathrm{K}$ e y w o r d s: young barley leaves, microwave-assisted extraction, flavonoids, antioxidant activity
\end{abstract}

\section{INTRODUCTION}

Fruit, vegetables and cereal crops are the natural sources of phytochemicals with antioxidant capacity (Shewfelt and Rosario, 2000; Yoo et al., 2008). In barley leaves, flavonoids are the major antioxidants which have strong free radical scavenging activity, anti-lipid oxidation activity (Cook and Samman, 1996), and may have the potential to inhibit platelet aggregation, lower low density lipoprotein (LDL), and protect the cardiovascular function (Formica and Regelson, 1995). In addition, young barley leaves have

*Corresponding author e-mail: min@jiangnan.edu.cn

**This work was financial supported by Jiangsu Province (China) Key Project in Agriculture (Contract No. BE2016362), Jiangsu Province (China) 'Collaborative Innovation Center for Food Safety and Quality Control' Industry Development Program, Jiangsu Province (China) Infrastructure Project (Contract No. BM2014051) which have enabled us to carry out this study (2016 -2018). been reported to possess other physiological and pharmacological activities including antidepressant (Yamaura et al., 2012), hypoglycemic (Venugopal and Iyer, 2010) and hypolipidemic (Yu et al., 2002) activities. Therefore, young barley leaves have the potential to be developed as functional foods/nutraceuticals.

Some researchers have reported the flavonoid compounds in young barley leaves (Benedet and Umeda, 2007). Osawa et al. (1992) reported that the main component was 2"-O-glucosylisovitexin, but isovitexin-7-O-glucoside (saponarin) was the major component in the research of Markham and Mitchell (2003). Recently, Ferreres et al. (2009) found that there were 26 different water soluble flavonoids in barley leaves and isoorientin-7-O-glucoside (lutonarin) was the main chemical. In another research conducted by Benedet et al. (2007), both saponarin and lutonarin were the main flavonoids in barley leaves with a ratio of saponarin/lutonarin $=4.5 / 1$.

The barley flavonoids belong to a group of flavone-Oglycoside, which has strong hydrophobicity due to its ion forms and salt characteristics with a sugar subunit. Water and ethanol are commonly used solvents to extract these flavonoids. However, the cost of ethanol extraction is relatively high and there could have some ethanol residue after the extraction which is not a desirable component in some products. Water extraction could overcome these shortcomings but conventional extraction (CE) generally consumes a large amount of water and the extraction time is very long, indicating low extraction efficiency (Pan et al., 2011). Therefore, microwave-assisted extraction (MASE) could be an alternative method to extract these flavonoids because of its high efficiency and relatively low

(C) 2017 Institute of Agrophysics, Polish Academy of Sciences 
cost (Routray and Orsat, 2012; Upadhyay et al., 2012). However, no information is available on the MASE of flavonoids from barley leaves.

The objective of the work was to optimise the conditions of MASE extraction of flavonoids from young barley leaves using water as solvent and response surface methodology (RSM). The major flavonoids were determined and the antioxidant activities of the extract were estimated.

\section{MATERIALS AND METHODS}

Dried young barley leaves were provided by Haitong Food Group Company, Cixi city, Zhejiang Province, China. The moisture content of the barley leaves was $5 \%$ (w.b.). Before experiment, the dried barley leaves were ground into powder through a 40 mesh sieve.

A NJL08-3 lab scaled microwave oven (Microwave Equipment Co., Ltd. China) was used in this extraction experiment, using three factors for the RSM design: microwave power, extraction time and liquid-solid ratio. A three factor and three level Box-behnken test optimiza- tion design was employed to fit a second order polynomial model which involved 17 treatments. The general equation of the second degree polynomial equation is:

$$
Y_{i}=\beta_{0}+\Sigma \beta i X_{i}+\Sigma \beta_{i i} X_{i}^{2}+\Sigma \beta_{i j} X_{i} X_{j}
$$

where: $Y_{i}$ is the predicted response value, $\beta_{0}$ is a constant, $\beta_{i}$ is the $i$ th linear coefficient, $\beta_{i i}$ is the quadratic coefficient, $\beta_{i j}$ is the linear-by-linear interaction, $X_{i}$ and $X_{j}$ are input variables. The test variables were transformed to range between -1 and 1, and the actual and coded levels of the independent variables used in the experimental design are shown in Table 1.

The dried barley leaf powder $(5.000 \mathrm{~g})$ was weighed into a flask, added with $150 \mathrm{ml}$ distilled water, and extracted twice at $70^{\circ} \mathrm{C}$ for $2 \mathrm{~h}$ each circle, that were based on pre-experiments. The filtrations of the two extractions were combined and transferred into a $500 \mathrm{ml}$ volumetric flask and adjusted to the volume with water.

T a b l e 1. Box-Behnken experimental design matrix with observed and predicted value

\begin{tabular}{cccccc}
\hline \multirow{2}{*}{ Number } & $\begin{array}{c}\text { Microwave power } \\
\left(\mathrm{W} \mathrm{g}^{-1}\right)\end{array}$ & $\begin{array}{c}\text { Extraction time } \\
(\mathrm{min})\end{array}$ & $\begin{array}{c}\text { Liquid-solid ratio } \\
\left(\mathrm{ml} \mathrm{g}^{-1}\right)\end{array}$ & $\mathrm{EV}$ & $\mathrm{FY}(\%)$ \\
\hline 1 & $-1(0.88)$ & $-1(4)$ & $0(30)$ & 71.92 & 72.85 \\
2 & $1(1.32)$ & -1 & 0 & 75.67 & 74.11 \\
3 & -1 & $1(12)$ & 0 & 70.43 & 71.99 \\
4 & 1 & 1 & 0 & 78.82 & 78.89 \\
5 & -1 & $0(8)$ & $-1(25)$ & 69.79 & 67.93 \\
6 & 1 & 0 & -1 & 71.22 & 71.86 \\
7 & -1 & 0 & $1(35)$ & 75.68 & 75.04 \\
8 & 1 & 1 & 77.42 & 79.28 \\
9 & $0(1.1)$ & -1 & -1 & 69.15 & 70.08 \\
10 & 0 & 1 & -1 & 69.96 & 70.25 \\
11 & 0 & -1 & 1 & 75.85 & 75.56 \\
12 & 0 & 1 & 1 & 80.23 & 79.30 \\
13 & 0 & 0 & 0 & 77.47 & 78.31 \\
14 & 0 & 0 & 0 & 78.45 & 78.31 \\
15 & 0 & 0 & 0 & 79.57 & 78.31 \\
16 & 0 & 0 & 0 & 79.01 & 78.31 \\
\hline
\end{tabular}

FY - flavonoids yield, EV - experimental values, PV - predicted values. 
The flavonoids in the barley leaves were determined by the method described by Liu and Zhou (2005) with some modifications. About $4 \mathrm{ml}$ extract sample was added in a $25 \mathrm{ml}$ volumetric flask, and $8.5 \mathrm{ml}$ ethanol solution $(30 \%$, w/w) was added. Another $0.7 \mathrm{ml} \mathrm{NaNO}_{2}$ solution $(5 \%)$ was added and after 5 min $0.7 \mathrm{ml} \mathrm{Al}\left(\mathrm{NO}_{2}\right)_{3}$ solution (10\%) was added and mixed. Six min later, $5 \mathrm{ml} \mathrm{NaOH}$ solution $\left(1 \mathrm{~mol} \mathrm{l}^{-1}\right)$ was added and the absorbance was recorded after $10 \mathrm{~min}$ on an UV-visible spectrophotometer UV-2600 (Shanghai Techcomp Instrument Co., Ltd, Shanghai, China) at $700 \mathrm{~nm}$ against a blank. The amount of the flavonoids was expressed as rutin equivalents (mg rutin $\mathrm{g}^{-1}$ sample) using a calibration curve of rutin.

About $84 \mathrm{ml}$ of crude flavonoid extract that obtained under the optimised MASE conditions was purified using a glass column $(20 \times 500 \mathrm{~mm})$ packed with $\mathrm{XAD}-2$ resin (Gold wheat company, China). After the sample was loaded on the column, $168 \mathrm{ml}$ of deionized water was eluted through it. Subsequently, the column was eluted with each of $50 \mathrm{ml}$ aqueous methanol solution $(30,50$, and $70 \%)$ in a series. The fractions were combined, evaporated in a rotary evaporator under vacuum at $30^{\circ} \mathrm{C}$, and then dissolved in $30 \mathrm{ml}$ of methanol. The solution was sonicated for $10 \mathrm{~min}$, filtered through a $0.45 \mu \mathrm{m}$ filter (F-type, Organic series, Sinoma Jinjing Fiberglass Co., Ltd., China) for HPLCMS analysis on a ZMD 4000 platform system (Waters Corporation, USA).

HPLC conditions: a $2.1 \times 100 \mathrm{~mm}, 1.7 \mu \mathrm{m}$, i.d. $\mathrm{CSH}$ C18 column (Waters Corporation, USA) was used for analysis of the flavonoids; mobile phase A: methanol; mobile phase B: $0.1 \%$ formic acid; flow rate of $0.3 \mathrm{ml} \mathrm{min}^{-1}$. The photodiode array detection wavelength was $200 \sim 600 \mathrm{~nm}$, the column temperature was $45^{\circ} \mathrm{C}$, and the injection volume was $1 \mu \mathrm{l}$.

MS conditions: using positive ion mode $\left(\mathrm{ESI}^{+}\right)$, capillary voltage, cone voltage, and extraction voltage of $3.5 \mathrm{kV}$, $30 \mathrm{~V}, 5 \mathrm{~V}$, respectively. The ion source temperature was $100^{\circ} \mathrm{C}$, desolvation temperature $250^{\circ} \mathrm{C}$, and flow electrospray ionization probe $70 \mathrm{ml}$ per minute. The mass scanning range was $\mathrm{m} / \mathrm{z} 100 \sim 1200$, with one scan time of $1 \mathrm{~s}$ and interval of $0.1 \mathrm{~s}$.

The barley leaf extracts from MASE were freeze dried into powders. Then the reducing power and DPPH radical scavenging activity were estimated.

The ferric reducing power of the freeze-dried extract was determined as described by Oyaizu (1986). The concentration of 1, 2, 3, 4, $5 \mathrm{mg} \mathrm{ml}^{-1}$ of the freeze-dried extract of MASE were prepared and kept at $4^{\circ} \mathrm{C}$ for $2 \mathrm{~h}$, respectively, and then centrifuged at 5000 r.p.m. for $30 \mathrm{~min}$. About $2.5 \mathrm{ml}$ samples, $2.5 \mathrm{ml}$ phosphate buffers $(0.2 \mathrm{M}$, $\mathrm{pH} 6.6$ ), and $2.5 \mathrm{ml}$ potassium ferricyanide ( $1 \%$ ) were mixed together and incubated at $50^{\circ} \mathrm{C}$ for $20 \mathrm{~min}$. After incubation, $2.5 \mathrm{ml}$ of $10 \%$ TCA (trichloroacetic acid) was added. The mixture was centrifuged at 5000 r.p.m. for $10 \mathrm{~min}$. A portion $(2.5 \mathrm{ml})$ of the supernatant was mixed with 2.5 $\mathrm{ml}$ deionized water and $0.5 \mathrm{ml}$ ferric chloride $(0.1 \%)$. After thoroughly mixed and allowed to rest for $10 \mathrm{~min}$, the absorbance was measured on the UV-2600 at $700 \mathrm{~nm}$ against a blank. Vitamin $\mathrm{C}(\mathrm{Vc})$ was used as the reference, and the absorbance of 10, 20, 30, 40,50 $\mu \mathrm{g} \mathrm{ml}^{-1}$ of Vc solutions were prepared and measured as above.

The antioxidant activity of the barley leaf extract on the 1,1-diphenyl-2-picrylhydrazyl free radical (DPPH.) was estimated according to the procedures described by Bhadoriya et al. (2012). An aliquot of 2, 4, 6, 8, $10 \mathrm{mg}$ $\mathrm{ml}^{-1}$ of the freeze-dried extract of MASE were prepared, and kept at $4^{\circ} \mathrm{C}$ for $2 \mathrm{~h}$, then centrifuged at 5000 r.p.m. for $30 \mathrm{~min}$. The supernatant of each sample $(1 \mathrm{ml})$ was mixed with $4.0 \mathrm{ml}$ of ethanol solution containing $0.1 \mathrm{mmol} \mathrm{l}^{-1}$ DPPH $.1 \mathrm{ml}$ ethanol was mixed $4.0 \mathrm{ml}$ of ethanol solution containing $0.1 \mathrm{mmol} \mathrm{l}^{-1} \mathrm{DPPH}$. The mixture was shaken thoroughly and placed at room temperature in the dark for $30 \mathrm{~min}$. The absorbance was measured at $517 \mathrm{~nm}$ on the UV-2600. The inhibition (I, \%) was calculated according to the formula:

$$
I=[1-(A i-A j) / A c] 100,
$$

where: $A c$ and $A i$ are the absorbance of the control and the sample, respectively, $A j-$ is the absorbance of ethanol. In order to eliminate the effect of the solvent on the absorbance of the sample.

Vitamin $\mathrm{C}$ was also used as the reference. About 20, $40,60,80,100 \mu \mathrm{g} \mathrm{ml}^{-1}$ of Vc solutions were prepared and measured as above.

The CE and MASE extraction experiments were conducted in triplicates and each analysis was done in duplicates. The averages were reported and significant differences among samples were considered when $p<0.05$, using the SPSS software version 15.0 for Windows (SPSS Inc., Chicago, IL, US) and ANOVA analysis with Duncan test.

\section{RESULTS AND DISCUSSION}

In the present study, microwave-assisted extraction (MASE) was employed for extracting flavonoids from the young barley leaves. The operational parameters were optimised using central composite rotatable design combined with response surface methodology.

Before the optimisation experiment, the main parameters independently influencing the MASE were preliminarily investigated, which were microwave power (varying from 0.44 to $1.32 \mathrm{~W} \mathrm{~g} \mathrm{~g}^{-1}$ ), extraction time (varying from 4 to $20 \mathrm{~min}$ ), liquid to solid ratio (varying from 10 to $35 \mathrm{ml}$ $\mathrm{g}^{-1}$ ) and extraction times (varying from 1 to 3 times). The extraction times was selected twice. The suitable microwave power was varied from 0.88 to $1.32 \mathrm{~W} \mathrm{~g}^{-1}$ and extraction time varied from 4 to $12 \mathrm{~min}$, as the flavonoid extraction yield appeared to be reduced when the power was beyond $1.32 \mathrm{~W} \mathrm{~g}^{-1}$ or below $0.88 \mathrm{~W} \mathrm{~g}^{-1}$, or the time beyond 12 min or below 4 min, respectivey. The suitable 
liquid to solid ratio was varied from 25 to $35 \mathrm{ml} \mathrm{g}^{-1}$, as the flavonoid extraction yield was comparatively stable. The three parameters in these ranges were used in the optimisation experiment by a $2^{3}$ full factorial central composite design. All experimental data obtained from 17 treatments and the predicted data from response surface analysis model were shown in Table 1.

The greater similarity of the experimental and predicted values from Table 1 indicates the accuracy of prediction of model for flavonoid extraction yield. The analysis of variance (ANOVA) shows that the experimental data for flavonoid extraction yield had a correlation coefficient $\left(\mathrm{R}^{2}\right)$ of 0.917 with the calculated model. In addition, $F$ value (8.60) of the model implied that the model is significant. The values of $p<0.05$ indicated that the model terms are significant. The $F$ value of lack of fit (4.95) and $p>0.05$ also showed that the model predictions are of high accuracy. The results suggested that the model worked well for the prediction of extracting flavonoids from young barley leaves by the MASE method.
Multiple regression analysis was utilized to represent the extraction yield of flavonoids $(\mathrm{Y}, \%)$ and thus a quadratic polynomial equation was derived from the regression analysis as following:

$$
\begin{aligned}
& \mathrm{Y}=78.31+2.04 \mathrm{X}_{1}+0.98 \mathrm{X}_{2}+3.63 \mathrm{X}_{3}+1.41 \mathrm{X}_{1} \mathrm{X}_{2}{ }^{+} \\
& 0.078 \mathrm{X}_{1} \mathrm{X}_{3}+0.89 \mathrm{X}_{2} \mathrm{X}_{3}-2.06 \mathrm{X}_{1}^{2}-1.79 \mathrm{X}_{2}^{2}-2.72 \mathrm{X}_{3}^{2} .
\end{aligned}
$$

The lower values of the variable $\mathrm{F}$ and $\mathrm{P}$ mean higher effect on the response. From Table 2, microwave power $\left(\mathrm{X}_{1}\right)$ had a significant effect $(\mathrm{p}<0.05)$, liquid-solid ratio $\left(\mathrm{X}_{3}\right)$ a very significant effect $(p<0.01)$, and microwave time $\left(X_{2}\right)$ had no significant effect ( $p>0.05)$ on the response. In addition, $\mathrm{X}_{1}^{2}$ and $\mathrm{X}_{3}^{2}$ had a significant effect $(\mathrm{p}<0.05), \mathrm{X}_{2}^{2}$ no significant effect $(p>0.05)$, and the interaction of the two factors had no significant effect $(p>0.05)$ on the response.

To get the maximum response values, the above quadratic equation was differentiated, and the suitable equations were obtained as following:

$$
\begin{aligned}
& 1.41 \mathrm{X}_{2}+0.078 \mathrm{X}_{3}-4.12 \mathrm{X}_{1}=-2.04, \\
& 1.41 \mathrm{X}_{1}+0.089 \mathrm{X}_{3}-3.58 \mathrm{X}_{2}=-0.98,
\end{aligned}
$$

\begin{tabular}{|c|c|c|c|c|c|c|}
\hline Source & Sum of squares & $\mathrm{df}$ & Mean squares & F value & $\mathrm{P}$ value & \\
\hline Model & 227.34 & 9 & 25.26 & 8.60 & 0.005 & Significant \\
\hline $\mathrm{X}_{1}$ & 33.25 & 1 & 33.25 & 11.32 & 0.012 & $*$ \\
\hline $\mathrm{X}_{2}$ & 7.70 & 1 & 7.70 & 2.62 & 0.149 & \\
\hline $\mathrm{X}_{3}$ & 105.56 & 1 & 105.56 & 35.93 & 0.001 & $* *$ \\
\hline $\mathrm{X}_{1} \mathrm{X}_{2}$ & 7.95 & 1 & 7.95 & 2.71 & 0.144 & \\
\hline $\mathrm{X}_{1} \mathrm{X}_{3}$ & 0.024 & 1 & 0.024 & 0.01 & 0.931 & \\
\hline $\mathrm{X}_{2} \mathrm{X}_{3}$ & 3.19 & 1 & 3.19 & 16.24 & 0.332 & \\
\hline $\mathrm{X}_{1}^{2}$ & 17.89 & 1 & 17.89 & 44.28 & 0.043 & $*$ \\
\hline $\mathrm{X}_{2}^{2}$ & 13.51 & 1 & 13.51 & 38.69 & 0.069 & \\
\hline $\mathrm{X}_{3}^{2}$ & 31.23 & 1 & 31.23 & 14.46 & 0.014 & $*$ \\
\hline Residual & 20.57 & 7 & 2.94 & & & \\
\hline Lack of fit & 16.20 & 3 & 5.40 & 4.95 & 0.078 & Not significant \\
\hline Error & 4.37 & 4 & 1.09 & & & \\
\hline Total & 247.91 & 16 & & & & \\
\hline $\mathrm{R}^{2}$ & 0.9170 & & & & & \\
\hline $\mathrm{R}_{\text {Adj }}^{2}$ & 0.8104 & & & & & \\
\hline C.V.\% & 2.28 & & & & & \\
\hline
\end{tabular}

T a b l e 2. Analysis of variance for regression model

${ }^{*} \mathrm{p}<0.05$ - significant, ${ }^{* *} \mathrm{p}<0.01$ - very significant. 


$$
0.078 X_{1}+0.089 X_{2}-5.44 X_{3}=-3.63 \text {. }
$$

The solutions were: $\mathrm{X}_{1}=0.7767, \mathrm{X}_{2}=0.7795, \mathrm{X}_{3}=0.8042$; This means the optimum conditions of MASE were microwave power $1.27 \mathrm{~W} \mathrm{~g}^{-1}$, extract time $11.12 \mathrm{~min}$, liquid-solid ratio $34.02 \mathrm{ml} \mathrm{g}^{-1}$, and extracted twice under the same conditions. The maximum predicted extraction yield of flavonoids (rutin equivalents) was $80.95 \%$.

From three-dimensional profiles, the response surface curves are able to show the interactions between any two factors (Pan et al., 2012). Figure 1a shows the effects of microwave power and extraction time on the extraction

a

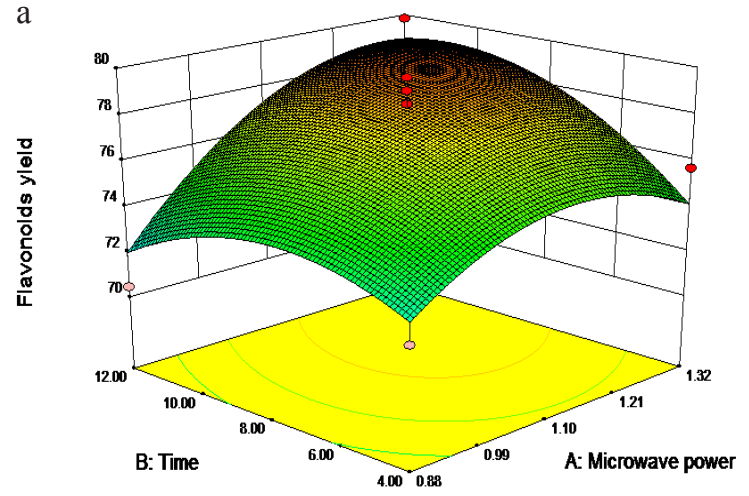

b

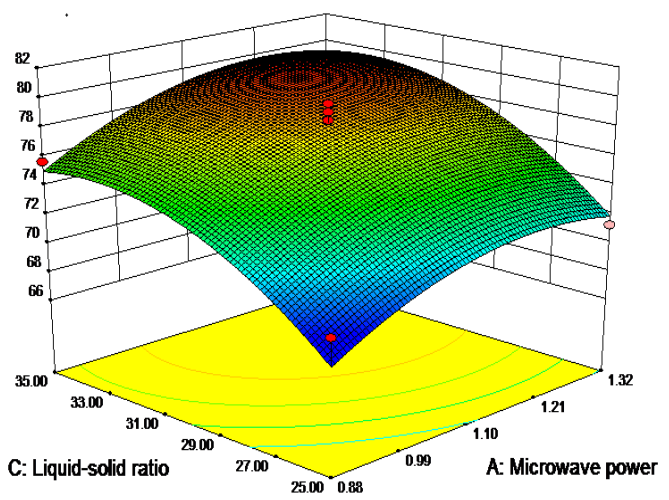

$\mathrm{c}$

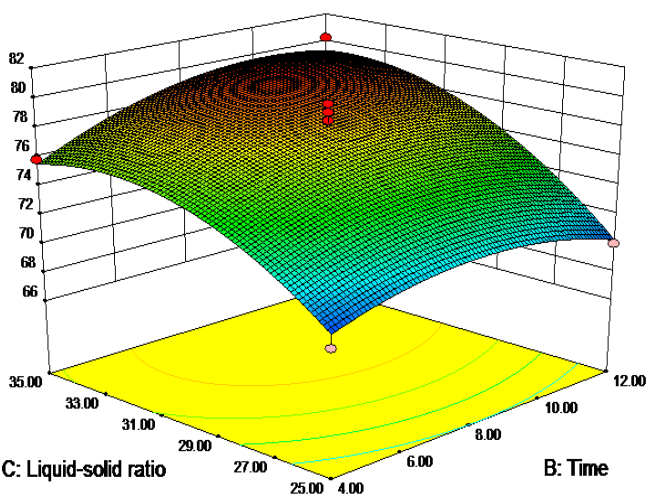

Fig. 1. Response surfaces for flavonoids-enriched extract from young barley leaves using microwave-assisted extraction: $\mathrm{a}-$ at varying microwave power and time, $\mathrm{b}$ - varying microwave power and liquid-solid ratio and $\mathrm{c}-$ varying time and liquid-solid ratio. yield of flavonoids under the fixed liquid-solid ratio conditions. Below the power of $1.27 \mathrm{~W} \mathrm{~g}^{-1}$, the extraction yield was significantly increased with the power increment $(\mathrm{p}<0.05)$, whereas when the power was above $1.27 \mathrm{~W} \mathrm{~g}^{-1}$, the extraction yield was decreased. The microwave extraction time showed no significance on the response value ( $>0.05$ ), but the extraction yield was increased with the extension of processing time below $11.12 \mathrm{~min}$. The flavonoid extraction yield was decreased when the extraction time was more than 11.12 min.

Figure $1 \mathrm{~b}$ shows the effects of liquid-solid ratio and microwave power on the flavonoid extraction yield under the fixed extraction time. The extraction yield increased significantly with the increase of liquid-solid ratio $(\mathrm{p}<0.01)$. As evident from Fig. 1b, increase of liquid-solid ratio from 25 to $34.02 \mathrm{ml} \mathrm{g}^{-1}$ and increase of microwave power from 4 to $11.27 \mathrm{~W} \mathrm{~g}^{-1}$ enhanced the extraction yield. However, the liquid-solid ratio of higher than $34.02 \mathrm{ml} \mathrm{g}^{-1}$ and microwave power above $11.27 \mathrm{~W} \mathrm{~g}^{-1}$ appeared to have adverse effect on the extraction of flavonoid. Figure $1 \mathrm{~b}$ indicated that a maximum level of flavonoids $(80.95 \%)$ could be achieved at the optimum point $\left(34.02 \mathrm{ml} \mathrm{g}^{-1}\right.$ liquid-solid ratio and $11.27 \mathrm{~W} \mathrm{~g}^{-1}$ microwave power).

Figure 1c shows the effects of liquid-solid ratio and microwave treatment time on the extraction yield of flavonoids under the fixed microwave power. It was observed that the highest extraction yield could be achieved when using $34.02 \mathrm{ml} \mathrm{g}^{-1}$ liquid to solid ratio for $11.12 \mathrm{~min}$. Increase of microwave treatment time from 4 to $11.12 \mathrm{~min}$ and increase of liquid-solid ratio from 25 to $34.02 \mathrm{ml} \mathrm{g}^{-1}$ accelerated the flavonoid extraction yield. The extraction yield was decreased when the extraction time was more than $11.12 \mathrm{~min}$ and liquid-solid ratio above $34.02 \mathrm{ml} \mathrm{g}^{-1}$.

Under the CE condition of liquid-solid ratio of $30 \mathrm{ml} \mathrm{g}^{-1}$ and extracted twice at $70^{\circ} \mathrm{C}$ for $2 \mathrm{~h}$, the flavonoid extraction yield was $75.31 \pm 0.73 \%$. However, the flavonoid extraction yield of MASE was $80.78 \pm 0.73 \%$ under the optimized conditions of microwave power $1.27 \mathrm{~W} \mathrm{~g}^{-1}$, time $11.12 \mathrm{~min}$, and liquid-solid ratio $34.02 \mathrm{ml} \mathrm{g}^{-1}$. The extraction time of MASE was much shorter which was only $6.18 \%$ of CE, but the extraction yield of flavonoids was significantly increased by $5.47 \%$ (Table 1). Thus, the results indicated that the MASE greatly reduced the extraction time, whereas the extraction yield was higher.

The HPLC-MS analysis showed that there were mainly two flavonoids (A and B) in the barley leaf extract, with their relative contents of 33.36 and $54.17 \%$, respectively. Their specific UV spectrum and mass spectrum were showed in Fig. 2. From the mass spectrum, the relative molecular weight of compounds A and B were 610 and 594 (Fig. 2b and 2c, respectively), which showed one more hydroxyl than those of the reported lutonarin and saponarin in the work of Benedet et al. (2007) and Kamiyama and Shibamoto (2012). Based on these information and references of Ferreres et al. (2008) and Markham and Mitchell 
a

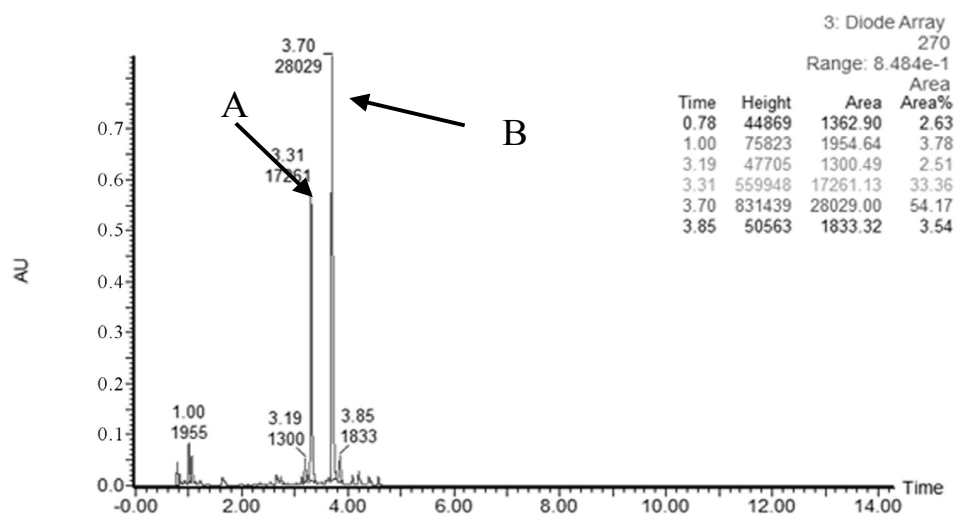

b
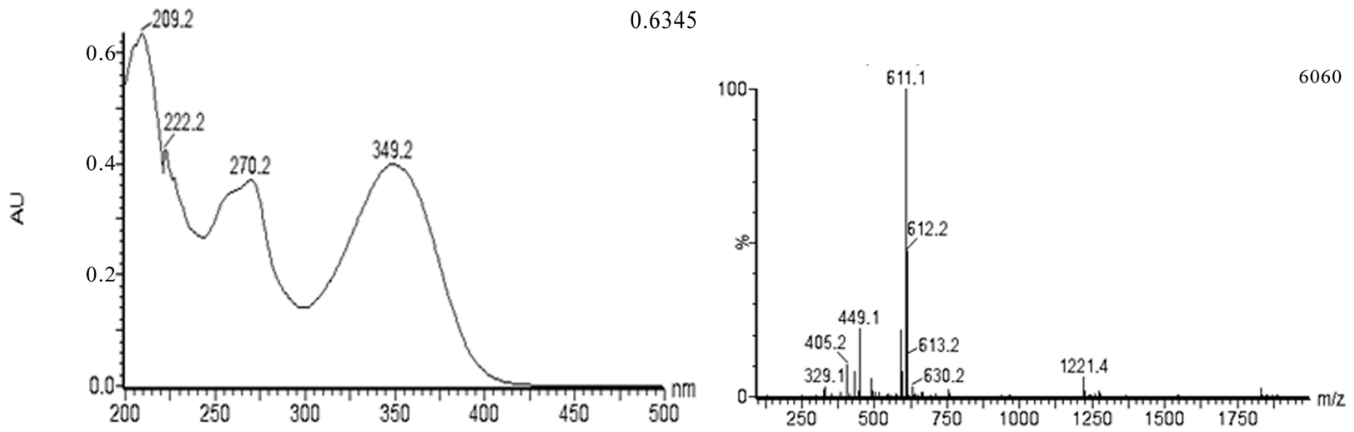

c
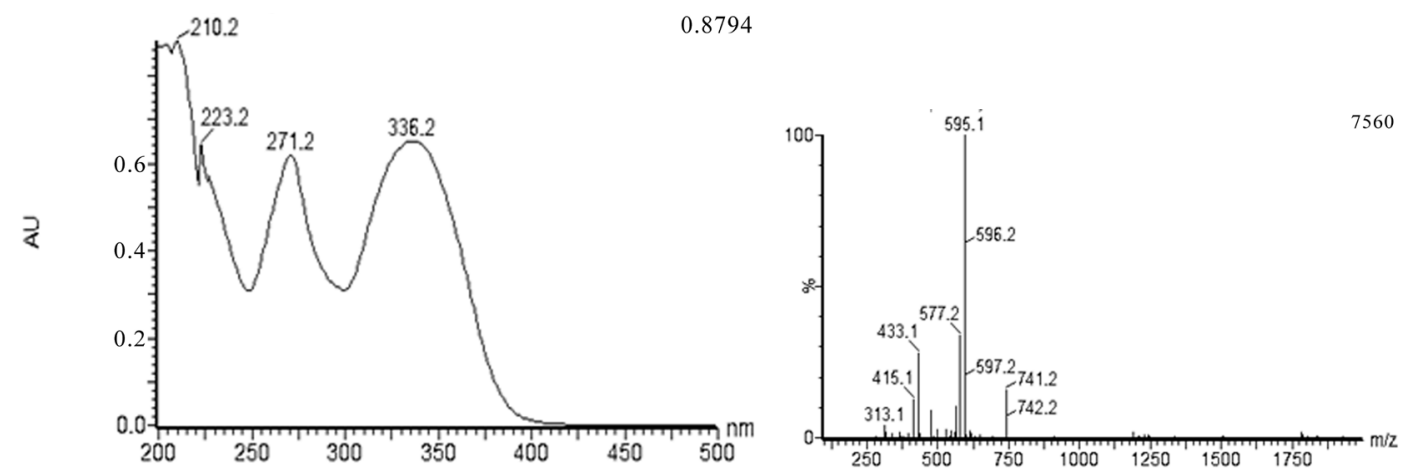

Fig. 2 HPLC-MS chromatogram of barley leaf flavonoids: a - HPLC chromatogram of barley leaf flavonoids, b - UV-vis spectra and TOF/MS fragment of peak A in Fig. (a), c - UV-vis spectra and TOF/MS fragment of peak B in Fig. (a).

(2003), it was estimated that A and B could be isoorientin7-O-glucoside and isovitexin-7-O-glucoside, respectively. However, the actual structure need further confirmation.

Using a reducing power assay, the presence of flavonoids reduces $\mathrm{Fe}^{3+}$ ferricyanid e complex into the ferrous form $\left(\mathrm{Fe}^{2+}\right)$. Therefore, $\mathrm{Fe}^{2+}$ can be monitored by measuring the formation of Perl Prussian blue at $700 \mathrm{~nm}$, and the greater the absorbance, the stronger is the antioxidant activity of the sample (Zhang et al., 2011). The reducing power of the barley leaf extract is shown in Fig. 3 with comparison of $\mathrm{Vc}$ as the reference. The results indicated that the reducing power of the MASE extract was ranged from 0.449 to 1.420 in the concentration of 1 to $5 \mathrm{mg} \mathrm{ml}^{-1}$. Compare with the reducing power of $\mathrm{Vc}, 1 \mathrm{mg} \mathrm{ml}^{-1}$ of young barley leaf was equivalent to about $14 \mu \mathrm{g} \mathrm{ml}^{-1} \mathrm{Vc}$.

The DPPH - is a stable free radical, which has been widely accepted as an index of estimating the free radicalscavenging activity of antioxidant (Nagai et al., 2003). The result of DPPH scavenging ability of the flavonoid extract is shown in Fig. 4 and also compared with that of Vc. The 


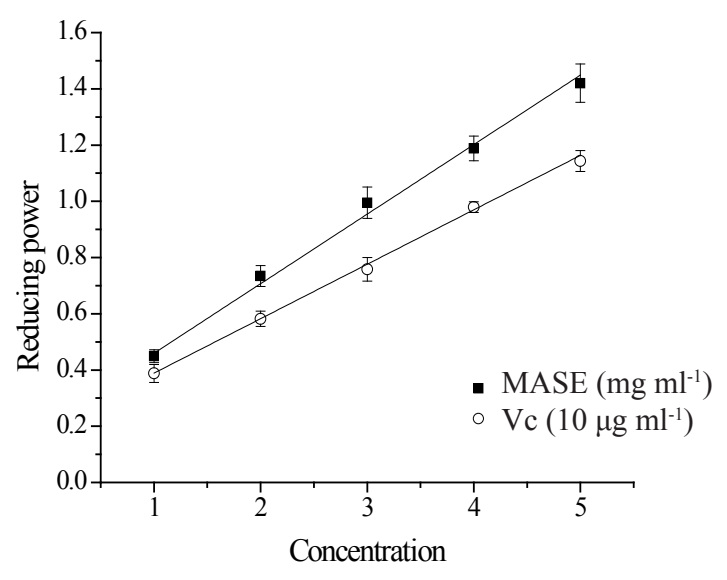

Fig. 3. The reducing power of barley leaf extract compared with Vc. Vc and MASE in the graphs are abscissa variable. $10 \mu \mathrm{g} \mathrm{ml}^{-1}$ is the unit of $\mathrm{Vc}$. The scale of Vc abscissa are 10, 20, $30,40,50 \mu \mathrm{g} \mathrm{ml}^{-1}$, the scale of MASE abscissa are $1,2,3,4,5$ $\mathrm{mg} \mathrm{ml^{-1 }}$.

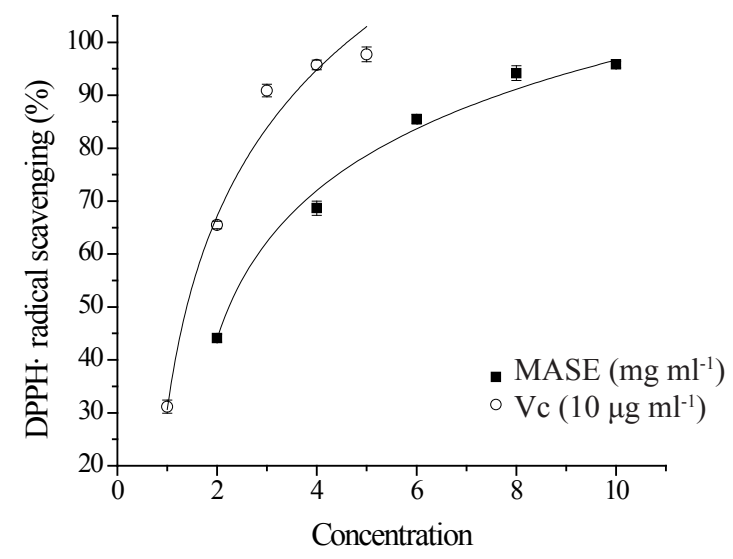

Fig. 4. DPPH radical scavenging capacity of barley leaf extract compared with Vc. Vc and MASE in the graphs are abscissa variable. $10 \mu \mathrm{g} \mathrm{ml}^{-1}$ is the unit of $\mathrm{Vc}$. The scale of $\mathrm{Vc}$ abscissa are $20,40,60,80,100 \mu \mathrm{g} \mathrm{ml}^{-1}$, the scale of MASE abscissa are 2,4, 6, $8,10 \mathrm{mg} \mathrm{ml}^{-1}$.

results indicated that the DPPH· radical scavenging activity was increased from $44.12 \pm 0.75$ to $95.81 \pm 0.63 \%$, when the concentration of the MASE extract was increased from 2 to $10 \mathrm{mg} \mathrm{ml}^{-1}$. Compared with the DPPH $\cdot$ radical scavenging activity of $\mathrm{Vc}, 1 \mathrm{mg} \mathrm{ml}^{-1}$ of the flavonoid extract of barley leaves was equivalent to about $5 \mu \mathrm{g} \mathrm{ml}^{-1} \mathrm{Vc}$, suggesting the barley leaf extract had a significant DPPH· radical scavenging activity.

\section{CONCLUSIONS}

This work optimized the extraction of flavonoids from young barley leaves using the microwave assisted extraction method and RMS. It provided a relatively simple, cost effective and efficient method in extraction of flavonoids from young barley leaves, which could be used to development of functional foods and nutraceuticals.

1. The optimal conditions of microwave assisted extraction were microwave power $1.27 \mathrm{~W} \mathrm{~g} \mathrm{~g}^{-1}$, extraction time $11.12 \mathrm{~min}$, liquid-solid ratio $34.02 \mathrm{ml} \mathrm{g}^{-1}$, and extracted twice under the same conditions. The microwave assisted extraction showed significantly higher efficiency than the conventional extraction method in extracting the flavonoids.

2 . The main components of the flavonoids in the barley leaf extract were probably $33.36 \%$ of isoorientin-7-O-glueoside and $54.17 \%$ of isovitexin-7-O-glucoside.

3. In addition, the extract exhibited strong reducing property as well as the DPPH radical scavenging activity. The results indicated that the young barley leaves are a good source of flavonoids and could be developed as functional foods/nutraceuticals.

Conflict of interest: The Authors do not declare conflict of interest.

\section{REFERENCES}

Benedet J.A., Umeda H., and Shibamoto T., 2007. Antioxidant activity of flavonoids isolated from young green barley leaves toward biological lipid samples. J. Agricultural Food Chem., 55(14), 5499-5504.

Bhadoriya U., Sharma P., and Solanki S.S., 2012. In vitro free radical scavenging activity of gallic acid isolated from Caesalpinia decapetala Wood. Asian Pacific J. Tropical Disease, (12), S833-S836.

Cook N. and Samman S., 1996. Flavonoids-chemistry, metabolism, cardioprotective effects, and dietary sources. J. Nutritional Biochemistry, 7(2), 66-76.

Ferreres F., Andrade P.B., Valentão P., and Gil-Izquierdo A., 2008. Further knowledge on barley (Hordeum vulgare L.) leaves O-glycosyl-C-glycosyl flavones by liquid chromatography-UV diode-array detection-electrospray ionisation mass spectrometry. J. Chromatography, A, 1182(1), 56-64.

Ferreres F., Krškova Z., Goncalves R.F., Vaentao P., Pereira J., Duse`k J., Martin J., and Andrade P.B., 2009. Free water-soluble phenolics profiling in barley (Hordeum vulgare L.). J. Agricultural Food Chem., 57(6), 2405-2409.

Formica J. and Regelson W., 1995. Review of the biology of quercetin and related bioflavonoids. Food Chemical Toxicology, 33(12), 1061-1080.

Kamiyama M. and Shibamoto T., 2012. Flavonoids with potent antioxidant activity found in young green barley leaves. J. Agric. Food Chem., 60(25), 6260-6267.

Liu J. and Zhou R.Q., 2005. Improvement of determination method of total flavonoids from bamboo leaves. Food Technology, 76-79. 
Markham K.R. and Mitchell K.A., 2003. The mis-identification of the major antioxidant flavonoids in young barley (Hordeum vulgare) leaves. Zettschrift Fur Naturforschung, C, 58(12), 53-56.

Nagai T., Inoue R., Inoue H., and Suzuki N., 2003. Preparation and antioxidant properties of water extract of propolis. Food Chemistry, 80(1), 29-33.

Osawa T., Katsuzaki H., Hagiwara Y., Hagiwara H., and Shibamoto T., 1992. A novel antioxidant isolated from young green barley leaves. J. Agric. Food Chem., 40(7), $1135-1138$.

Oyaizu M., 1986. Studies on products of browning reactions: Antioxidative activities of products of browning reaction prepared from glucosamine. J. Nutrition, 44, 307-315.

Pan G., Yu G., Zhu C., and Qiao J., 2012. Optimization of ultrasound-assisted extraction (UAE) of flavonoids compounds (FC) from hawthorn seed (HS). Ultrasonics Sonochemistry, 19(3), 486-490.

Routray W. and Orsat V., 2012. Microwave-assisted extraction of flavonoids: a review. Food Bioprocess Technol., 5(2), 409-424.

Shewfelt R.L. and Del Rosario B.A., 2000. The role of lipid peroxidation in storage disorders of fresh fruits and vegetables. HortScience, 35(4), 575-579.
Upadhyay R., Ramalakshmi K., and Jagan Mohan Rao L., 2012. Microwave-assisted extraction of chlorogenic acids from green coffee beans. Food Chem., 130(1), 184-188.

Venugopal S. and Iyer U.M., 2010. Management of diabetic dyslipidemia with subatmospheric dehydrated barley grass powder. Int. J. Green Pharmacy, 4(4), 251-256.

Yamaura K., Nakayama N., Shimada M., Bi Y., Fukata H., and Ueno K., 2012. Antidepressant-like effects of young green barley leaf (Hordeum vulgare L.) in the mouse forced swimming test. Pharmacognosy Research, 4(1), 22-26.

Yoo K.M., Lee C.H., Lee H., Moon B., and Lee C.Y., 2008. Relative antioxidant and cytoprotective activities of common herbs. Food Chem., 106(3), 929-936.

Yu Y.-M., Wu C.-H., Tseng Y.-H., Tsai C.E., and Chang W.-C., 2002. Antioxidative and hypolipidemic effects of barley leaf essence in a rabbit model of atherosclerosis. Japanese J. Pharmacology, 89(2), 142-148.

Zhang G., He L., and Hu M., 2011. Optimized ultrasonic-assisted extraction of flavonoids from Prunella vulgaris L. and evaluation of antioxidant activities in vitro. Innovative Food Science Emerging Technol., 12(1), 18-25. 